\title{
SCIDiC
}

International Journal of Dentistry and Oral Science (IJDOS)

ISSN: 2377-8075

\section{Periodontal Health Status And Periodontal Treatment Needs Of Prisoners In Two Jails In Khartoum State}

Research Article

\author{
Magzoub A ${ }^{1}$, Tawfig $\mathrm{N}^{2 *}$, Satti $\mathrm{A}^{3}$, Gobara $\mathrm{B}^{4}$ \\ ${ }^{1}$ Department of Periodontology, Faculty of Dentistry, University of Khartoum, Sudan. \\ ${ }^{2}$ Assistant Professor, Department of Periodontology, Faculty of Dentistry, University of Khartoum, Sudan. \\ ${ }^{3}$ Master Degree in Restorative Dentistry, Federal Ministry of Health. \\ ${ }^{4}$ Associate Professor, Department of Periodontology, Faculty of Dentistry, University Of Khartoum, Sudan.
}

Abstract

Background: Prisoner is a person who is deprived of his/her freedom; even though they are deprived of their freedom they are not deprived of their right to maintain good general and oral health. Limited studies have been conducted among prisoners. Therefore the present study aimed to assess the periodontal health status and treatment needs of prisoners in two jails in Khartoum state.

Methodology: A total of 389 prisoners were selected from two different prisons in Khartoum State. A pro-forma was used to obtain data regarding socio-demographic characteristics, duration of stay in prison, and oral hygiene habits. The W.H.O. Oral Health Assessment Form (1997) was used to assess the oral health status of the study subjects.

Results: 237 of prisoners were males and 152 were females in the age group of $17-65$ years. $35.9 \%$ of prisoners were imprisoned for less than 6 months. The majority of the prisoners were illiterate (37.3\%). The highest number of individuals $(52.7 \%)$ was classified as CPITN of which implies that they need oral hygiene instruction, $33.7 \%$ score CPTN of 2 , while only $2.6 \%$ of the prisoners scored a CPITN of 4 and they need scaling and surgical periodontal treatment.

Conclusion: There is an observant need of oral health care programmes as the standard of periodontal health observed among prisoners is low, and ultimately the respondents will be returning to the community.

Keywords: Prisoners; CPITN; PI and GI.

\section{Introduction}

Oral health is central to general health and is one of the valuable assets not only for an individual but also for the social system. Despite great attainments in the oral health of populations worldwide, problems still remain in many communities around the world, particularly among the disadvantaged and vulnerable groups [1].

Prisoners constitute one of the disadvantaged group as these people are solitary confined for long duration and hence are socially and economically deprived from the community [2].

The prisoner's area represents a psychologically, socially, morally and economically affected group and this drives them to neglect their general as well as oral health. Prisoners are vulnerable to a wide range of health problems, most commonly alcohol and drug abuse, smoking, chronic diseases, mental illness, psychosocial and psychiatric problems. Moreover, prisoners are at a higher risk of violence among themselves, which results in the development of high chronic stress levels, which may deteriorate the physical and mental health [3]. Additionally, excessive alcohol consumption, particularly spirits, and tobacco use increases the prevalence and severity of periodontal disease and are by far the greatest risk factors for oral cancer [4].

Periodontal diseases are the most common human dental diseases affecting the population all over the world. As the prevalence and severity of periodontal diseases are high among population, pre-

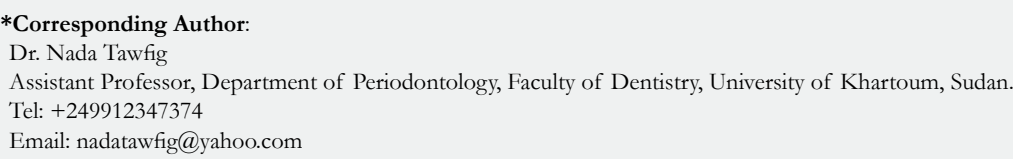

Citation: Magzoub A, Tawfig N, Satti A, Gobara B (2016) Periodontal health status and periodontal treatment needs of prisoners in two jails in Khartoum State. Int J Dentistry Oral Sci 03(4), 233-238. doi: http://dx.doi.org/10.19070/2377-8075-1600048

Copyright: Nada Tawfig ${ }^{\circ}$ 2016. This is an open-access article distributed under the terms of the Creative Commons Attribution License, which permits unrestricted use, distribution and reproduction in any medium, provided the original author and source are credited. 
vention and treatment of these diseases are of the most serious problems of modern dentistry [5].

Oral health status of individuals in the prison environment is an area that is currently under-researched [6]. Prisoners are a vulnerable and socially deprived group requiring special consideration as they are often neglected with little or no access to oral health care [7].

Their is olated environment makes them more depressed which affects the systemic as well as oral health of the body and problems like periodontitis become more prevalent $[8,9]$.

Furthermore, current evidence supports the finding that these high levels of periodontal disease have an impact on the prisoners' quality of life [10].

The high level of periodontal disease among prisoners is likely due to the lack of a standardized system for the assessment and prioritization of the dental needs of prisoners. Unfortunately, their dental needs do not appear to be met during their admission time. Possible explanations for this could the limited mobility of prisoners within the prison system, the restricted number of dental sessions provided in prisons and perhaps the lack of flexibility due to security concerns [11].

According to the Sudanese national prisons authority, there has been a total of about 20,000 prisoners in four jails in Khartoum state. Since oral health information of such prisoners is scarce, the objective of the present study was to assess the periodontal health status and treatment needs of prisoners in two prisons in Khartoum State.

\section{Material and Methods}

The present study was conducted among the prisoners in two prisons in Khartoum state (Elhoda Institutional City, Dar altaiebatWomen prison) during the period from august 2015 to December 2015. The sample size was calculated and it was 386 prisoners, to insure randomization a systematic sampling procedure using online randomization program (http://www.randomization.com) was used.

Official permission was obtained from the head of the jail and jail authorities before conducting the study. The details of the nature and purpose of the st udy were described verbally, and in writing, via the consent form. A written informed consent was obtained from all the participants before undergoing an oral examination.

All prisoners who were willing to give the consent were included in the study. The subjects who did not give their consent for oral examination were excluded.

The required data was collected and recorded using pro-forma which consisted of three sections; the 1 st section was a structured questionnaire which validated through a pilot survey prior to initialization of the study, to obtain data regarding socio-demographic characteristics, duration of stay in the prison, previous dental treatment in prison and oral hygiene practices, in addition to educational level.
Aforementioned information was collected by interview method. The second section was periodontal examination sheet to record the Plaque index (PI Silness and Loe 1964) and the Gingival Index (GI Loe and Silness 1963) [12,13].

The third section was Assessment of the periodontal status using WHO Oral Health Assessment Form (1997) [14].

\section{Examination}

The oral examination of the subjects was carried out under natural day light using standard explorers, mouth mirrors and CPITN probes (designed by WHO/IDF) with applying a gentle probing force (20 $\mathrm{g}$ or lower) according to WHO criteria [5].

Plaque index (PI Silness and Loe 1964, Gingival Index (GI) Loe and Silness 1967) were detected and recorded in data sheet. The oral examination took on an average 7 to 9 minutes to be completed.

The examination was carried out by one examiner (Elmagzoub. A), the intra-examiner reliability for various recordings ranged from 0.80 to 0.91 . Proper sterilization was maintained during the examination.

The information obtained analyzed using Statistical Package of Social Sciences (SPSS) software version 22 by a statistician. Chisquare test used to test the association between categorical variables. Independent student $T$ test and one way ANOVA used for comparison of means.

\section{Results}

A total of 389 prisoners participated in this survey 237 males from Alhuda institutional city prison and 152 females from Dar altaiebat women prison (Figure 1).

Those who were selected were invited to participate and informed on the aims and objectives of the study. Only those who provided written consent were eligible to take part in this survey.

The mean age of the study population was 34.07 with maximum age 65 and minimum age of 17 , the mean age for males was 34.91 and for females was 32.75 .

The accumulative mean time spent inside the prison was 23.86 months for the whole study population with the minimum time of 1 month and maximum of 120 months; the mean time spent inside the prison for males was $33.51 \pm 28.25$ months while in females the mean time spent inside the prison was $8.82 \pm 12.81$ months.

\section{Distribution of study population according to literacy status}

The education level varied among the prisoners with the majority of them were illiterate 145 prisoners $(37.3 \%)$, the prisoners who studies till primary school were $128(32.9 \%)$ and those who reach secondary school and university level were $82(21.1 \%), 34(8.7 \%)$ respectively (Figure 2). 
Figure 1. Percentage of Study Population From Each Jail.

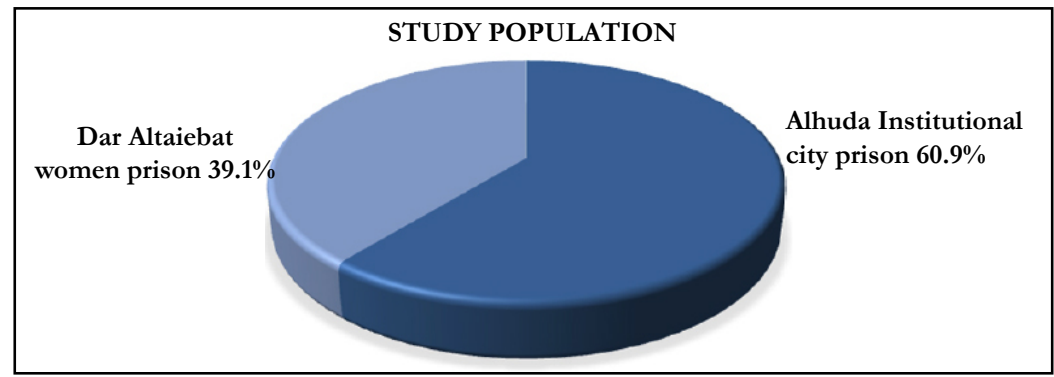

Figure 2. Education Levels of The Prisoners.

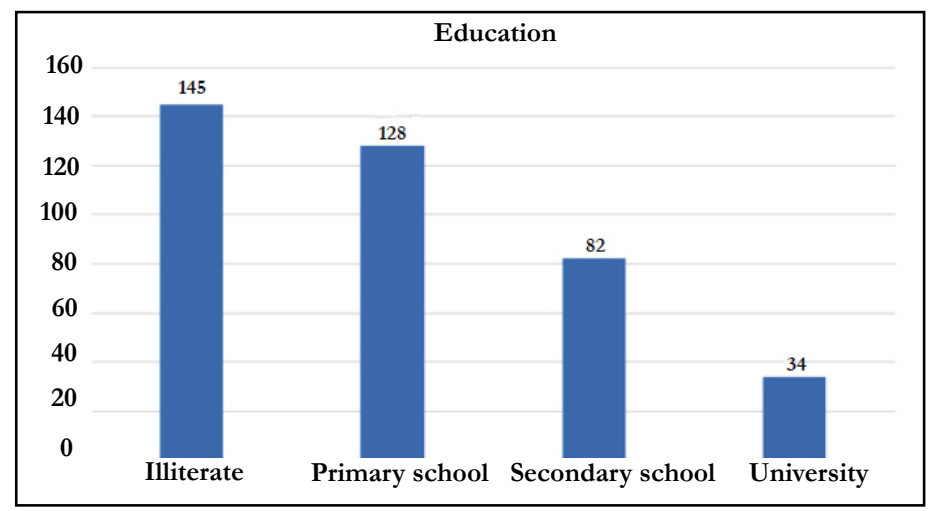

Distribution of the study population based on Oral Hygiene Aids Used

Regarding the oral hygiene of the study population, $102(26.2 \%)$ stated that they brush their teeth one time per day, while 287 $(73.8 \%)$ brush their teeth more than one time per day, furthermore 359 prisoners $(92.3 \%)$ use tooth brush, 18 prisoners $(4.6 \%)$ use Miswak and 12 prisoners (3.1\%) use both tooth brush and Miswak. (Table 1).

\section{PI and GI of the study population}

The mean plaque index for the study population was $1.27 \pm$ while the mean gingival index was $1.45 \pm$.

\section{Periodontal treatment need of the study population.}

About $3.6 \%$ of the prisoners were found to have completely healthy periodontal tissues and were classified in a CPITN value of 0 with no treatment need; the highest number of individuals $(52.7 \%)$ was classified as CPITN score of 1 which implies that they need oral hygiene instructions. Moreover, $3.7 \%$ of subjects scored CPTN of 2 which implies that they have calculus and need scaling and polishing with oral hygiene instruction, while $7.5 \%$ had score of 3 which need deep scaling and oral hygiene instruction.Only $2.6 \%$ of the prisoners scored CPTN of 4 and they need scaling and surgical periodontal treatment.

\section{Distribution of PI and GI according to gender}

When a comparison was made between males and females in regards to their PI and GI, the mean PI for males was $1.26 \pm 0.32$ and that for females was $1.29 \pm 0.40$. On the other hand, the mean GI for males was 1.46 \pm 0.19 , while that for females was $1.44 \pm 0.25$.

The difference in means of PI and GI among males and females was statistically not significant.(Table 2).

\section{CPITN according to gender}

The distribution of CPTIN in genders illustrated significant results $(\mathrm{P}$ value $=0.001)$, with females having a CPITN score of 0 value which indicates healthy gingival tissues. Furthermore, $4.2 \%$ of male prisoners scored a CPTIN of 4 , indicative of a periodontal pocket more than 5.5 which necessitates complex periodontal treatment.

None of the females obtained a CPTIN score of 4 . The majority of the male prisoners had a CPITN of 1 value $(56.1 \%)$, while $35 \%$ of male prisoners scored a CPTIN of 2 . In addition to that, the majority of females (47.4\%) scored a CPTIN of 1 and $31.6 \%$ scored a CPITN of 2 . Only $4.6 \%$ of males and $11.8 \%$ of females scored a CPTIN of 3. (Table 3).

PI and GI of the study population according to duration of imprisonment

Upon comparison of the period spent inside the prison the study population was distributed into three groups; 140 prisoners spent 6months and less, 121 prisoners stayed between 7 and 24 months and the remaining 128 prisoners stayed more than 24 months.

The means PI and GI for the 6 months and less were $1.30 \pm 0.35$ and $1.43 \pm 0.25$ respectively, while those of the second group were $1.25 \pm 0.34$ and $1.42 \pm 0.15$ correspondingly. In the last group the mean PI was $1.26 \pm 0.36$ and the mean GI was $1.50 \pm 0.23$. (Table $4,5)$.

CPITN of the study population according to Duration of Imprisonment

When correlating the CPTIN score and the period spent inside 
the prison a significant result was revealed $(\mathrm{P}$ value $=0.001)$. Only prisoners who spent more than 24 months inside prison, scored a CPTIN of 4 . The majority of prisoners $(55 \%)$ who spent less than 6 months scored a CPTIN of 1 , while $63 \%$ of the prisoners who spent between 7 and 24 months inside prison scored a CPITN of 1 . The majority of the prisoners who spent more than 24 month inside prison (46.1\%) scored a CPTIN of 2.

Finally, about $4.3 \%$ from the prisoners who spent less than 6 months scored a CPTIN of 0 , and $5 \%$ of the prisoners who spent from 7 to 24 months scored a CPTIN of 0 , while only $1.6 \%$ from prisoners who spent more than 24 months scored a CPTIN of 0 (Table 6).

\section{Discussion}

The prison population is a distinctive and challenging one with many problems, including poor health. Prisoners are more susceptible to a wide range of health problems [15].

Table 1. The oral hygiene practice of the prisoners.

\begin{tabular}{|l|l|l|l|}
\hline & & Frequency & Percent \\
\hline Brushing & One time & 102 & 26.2 \\
\hline & Two and more & 287 & 73.8 \\
\hline Method & Tooth brush and paste & 359 & 92.3 \\
\hline & Miswak & 18 & 4.6 \\
\hline & Both & 12 & 3.1 \\
\hline & Total & 389 & 100 \\
\hline
\end{tabular}

Table 2: PI and GI scores of the prisoners

\begin{tabular}{|c|c|c|c|c|c|c|c|}
\hline & & \multirow{2}{*}{$\mathbf{N}$} & \multirow{2}{*}{ Mean } & \multirow{2}{*}{ SD } & \multicolumn{2}{|c|}{$95 \%$ CI of Mean } & \multirow{2}{*}{$\begin{array}{c}\text { P value* } \\
0.526 \\
\end{array}$} \\
\hline & & & & & Lower Bound & Upper Bound & \\
\hline \multirow{2}{*}{ PIMean } & Male & 237 & 1.26 & 0.32 & 1.22 & 1.3 & \\
\hline & Female & 152 & 1.29 & 0.4 & 1.22 & 1.35 & \\
\hline \multirow{2}{*}{ GIMean } & Male & 237 & 1.46 & 0.19 & 1.43 & 1.48 & 0.593 \\
\hline & Female & 152 & 1.44 & 0.25 & 1.4 & 1.48 & \\
\hline
\end{tabular}

*Independent student's T test performed, P value is not significant

Table 3: Distribution of CPTIN by gender

\begin{tabular}{|c|c|c|c|c|c|c|}
\hline & Score 0 & Score 1 & Score 2 & Score 3 & Score 4 & Total \\
\hline \multirow{2}{*}{ Male } & 0 & 133 & 83 & 11 & 10 & 237 \\
\cline { 2 - 7 } & $0.00 \%$ & $56.10 \%$ & $35.00 \%$ & $4.60 \%$ & $4.20 \%$ & $100.00 \%$ \\
\hline \multirow{3}{*}{ Female } & 14 & 72 & 48 & 18 & 0 & 152 \\
\cline { 2 - 7 } & $9.20 \%$ & $47.40 \%$ & $31.60 \%$ & $11.80 \%$ & $0.00 \%$ & $100.00 \%$ \\
\hline \multirow{2}{*}{ Total } & 14 & 205 & 131 & 29 & 10 & 389 \\
\cline { 2 - 7 } & $3.60 \%$ & $52.70 \%$ & $33.70 \%$ & $7.50 \%$ & $2.60 \%$ & $100.00 \%$ \\
\hline
\end{tabular}

$*$ Chi squire test performed, $\mathrm{p}$ value $=0.001, \mathrm{P}$ value is significant

Table 4: PI in relation to time spent inside the prison

\begin{tabular}{|c|c|c|c|c|c|}
\hline & \multirow{2}{*}{$\mathbf{N}$} & \multirow{2}{*}{ Mean } & \multirow{2}{*}{ SD } & \multicolumn{2}{|c|}{$\mathbf{9 5 \% \text { Confidence Interval for Mean }}$} \\
\cline { 5 - 6 } & & & & Lower Bound & Upper Bound \\
\hline 6 months and less & 140 & 1.3 & 0.35 & 1.24 & 1.36 \\
\hline 7 - 24 months & 121 & 1.25 & 0.34 & 1.19 & 1.31 \\
\hline More than 24 months & 128 & 1.26 & 0.36 & 1.2 & 1.32 \\
\hline Total & 389 & 1.27 & 0.35 & 1.24 & 1.31 \\
\hline
\end{tabular}

$*$ One way ANOVA, $\mathrm{p}$ value $=0.412, \mathrm{P}$ value is not significant 
Table 5: GI in relation to Time spent inside the prison

\begin{tabular}{|c|c|c|c|c|c|}
\hline & \multirow{2}{*}{$\mathbf{N}$} & \multirow{2}{*}{ Mean } & \multirow{2}{*}{ SD } & \multicolumn{2}{|c|}{$\mathbf{9 5 \%}$ Confidence Interval for Mean } \\
\cline { 5 - 6 } & & & & Lower Bound & Upper Bound \\
\hline 6 months and less & 140 & 1.43 & 0.25 & 1.39 & 1.47 \\
\hline 7 - 24 months & 121 & 1.42 & 0.15 & 1.39 & 1.45 \\
\hline More than 24 months & 128 & 1.5 & 0.23 & 1.46 & 1.54 \\
\hline Total & 389 & 1.45 & 0.22 & 1.43 & 1.47 \\
\hline
\end{tabular}

$*$ One way ANOVA, $\mathrm{p}$ value $=0.009, \mathrm{P}$ value is significant

Table 6. CPITN In Relation To Period Spent Inside.

\begin{tabular}{|c|c|c|c|c|c|c|}
\hline & Score 0 & Score 1 & Score 2 & Score 3 & Score 4 & Total \\
\hline \multirow{2}{*}{ 6 months and less } & 6 & 77 & 36 & 21 & 0 & 140 \\
\cline { 2 - 7 } & $4.30 \%$ & $55.00 \%$ & $25.70 \%$ & $15.00 \%$ & $0.00 \%$ & $100.00 \%$ \\
\hline \multirow{2}{*}{7 - 24 months } & 6 & 77 & 36 & 2 & 0 & 121 \\
\cline { 2 - 7 } & $5.00 \%$ & $63.60 \%$ & $29.80 \%$ & $1.70 \%$ & $0.00 \%$ & $100.00 \%$ \\
\hline \multirow{2}{*}{ More than 24 months } & 2 & 51 & 59 & 6 & 10 & 128 \\
\cline { 2 - 7 } & $1.60 \%$ & $39.80 \%$ & $46.10 \%$ & $4.70 \%$ & $7.80 \%$ & $100.00 \%$ \\
\hline Total & 14 & 205 & 131 & 29 & 10 & 389 \\
\hline & $3.60 \%$ & $52.70 \%$ & $33.70 \%$ & $7.50 \%$ & $2.60 \%$ & $100.00 \%$ \\
\hline
\end{tabular}

$*$ Chi square test performed, $\mathrm{p}$ value $=0.001, \mathrm{P}$ value is significant.

Dental diseases, including periodontal diseases can reach epidemic proportions in the prison settings [2].

The purpose of the present study was to assess the periodontal health status and periodontal treatment needs of the prisoners in two main Jails in Khartoum state.

Regarding the sociodemographic characteristics of the current study population, the mean age was found to be similar to other studies done by Nobile et al, Heidari et al and Braimoh et al on the other hand, male to female ratio (6:1) was as well comparable to other studies $[16,17]$, though most studies were conducted mainly among male prisoners [18]. Only one study was found to be conducted exclusively on female inmates [16].

The majority of our study population was illiterate and that is concordant with the result of a study done by Anup et al. [3]. However, our results showed higher percent of university and post graduate level than those obtained by Anup et al. [3].

According to oral hygiene behavior, most of the prisoners used tooth brush and paste which is comparable to the results of Heidari et al [9]. The percentage of chew stick users was 4.6\% which was much lower than Bhat et al. in their study among tribal community[19].

Difference in the percentage of chew stick users could be due to less availability of sticks in the prison premises. Other studies reported the use of twigs of the arak tree as oral hygiene tools among prisoners in different countries and this reflects the fact that those populations are still having the same attitude towards oral health based on their believes and cultural background [20]. Despite the fact that the majority of participants $(73.8 \%)$ reported brushing their teeth more than one time per day, the prisoners presented with higher plaque and gingival indices when compared with studies by Nobile et al and Heidari et al $[6,9]$.

The high PI and GI contradicted the reported oral hygiene practices by the prisoners and leads to the assumption that the prisoners may have been reporting what they felt the researcher wanted to hear. In addition to the fact that most of the prisoners in the present study were illiterate and do oral hygiene practices only for namesake and show little concern for cleanliness beside the possibility of improper brushing technique that help in plaque accumulation.

Regarding CPITN, only $3.6 \%$ of the subjects were found to have healthy periodontal tissues and were classified in a CPI value of 0 with no treatment need. The majority of subjects recorded CPI score of one or more with the highest numbers of individuals being classified as CPI of 1 . This finding is consistent with studies conducted in India and Nigeria [21, 22], but is contradicted with another study in Italy [6], that found $10.5 \%$ of prisoners with healthy periodontal tissues, $89.5 \%$ had a CPITN score of one or more. However, the majority of prisoners $(39 \%)$ had a CPI score of 2. Difference in the results might be due to lack of oral health services in the prison where this study was carried out, such prisoners are not exposed to oral health education and information about oral health.

When comparing the plaque index (PI) and the gingival index (GI) of the male prisoners and female prisoners it has been revealed that there was no statistically significant difference. However, in many other studies women have fared better than men when assessing PI and GI [23]. 
Comparison between males and females in CPTIN score revealed that only female prisoners have healthy periodontal tissues with a statistically significant value, and only male prisoners scored a CPTIN of 4 which agrees with the finding of Braimoh et al [22]. The majority of male prisoners scored a CPTIN of 1 while the females were distributed between the score of 1 and 2 which implicates that males and females need to reinforce their oral hygiene instructions and scaling by dentists.

When investigating the period of stay inside the prison, the study population was categorized into 3 groups; the prisoners who stayed less than 6 months, prisoners who stayed from 7 to 24 months and those who stayed more than 24 months. Upon comparison of the PI and GI among those groups, it was found that the more the prisoners stayed inside the jail, the worse their periodontal health became. This finding is coincides with the work of Anup et al [3], which could be explained by the psychological problems and the stress that raised from long stay away from the society with a consequent loss of will to be in good general and oral health in addition to the absence of regular dental visits.

The same was found regarding the CPITN, the more time prisoners stayed inside the prison the worse the CPTIN became, which is in accordance with a study by Anup et al [3]. In addition, a significant difference was detected in CPI scores among the prisoners with respect to the period of imprisonment, and this is similar to the result of the present study. This might also be due to stress which can lead to progression of periodontal disease beside the lack of dental health services inside the prisons.

\section{Limitations of the Study}

The major limitation of the study was its cross sectional design. Additionally more refined and informational results could be attained if the present study extrapolation would be compared with non-prisoner population, questioned and examined by the same codes and criteria.

\section{Conclusion}

The results of the present study highlighted a need for special attention from government sector and other health organizations to meet the basic oral health needs of this community as high CPITN score was detected which ultimately showed positive correlation with lack of oral hygiene practices, deprivation of social life, and overall quality of life in the jail setting. Also oral health care programmes should be organized for prisoners in order to educate them regarding proper oral hygiene practices.

\section{References}

[1]. Petersen PE (2004) Improvement of oral health in Africa in the 21st century - The role of the WHO Global Oral Health Programme. Developing Dentistry 5(1): 9-20.

[2]. Freudenberg N (2001) Jails, Prisons and the Health of Urban Populations: A Review of the Impact of the Correctional System on Community Health. J Urban Health 78(2): 214-234.

[3]. Anup N, Biswas G, Vishnani P, Tambi S, Acharaya S, et al. (2014) Oral Health Status and Treatment Needs Of Inmates in District Jail of Jaipur City - A Cross Sectional Study. IOSR Journal of Nursing and Health Science 3(3): 22-31

[4]. Berkman A (1995) Prison health: the breaking point. Am J Public Health 85(12): 1616-1618.

[5]. Ainamo J, Barmes D, Beagric G, Cutress T, Martin J, et al. (1982) Develop- ment of the World Health Organization (WHO) Community Periodontal Index of Treatment Needs (CPITN). Int Dent J 32(3): 281-291.

[6]. Nobile CG, Fortunato L, Pavia M, Angelillo IF (2007) Oral health status of male prisoners in Italy. Int Dent J 57(1): 27-35.

[7]. Osborn M, Butler T, Barnard PD (2003) Oral health status of prison inmates - New South Wales, Australia. Aust Dent J 48(1): 34-38.

[8]. Lindquist CH, Lindquist CA (1999) Health behind bars: utilization and evaluation of medical care among jail inmates. J Community Health 24(4): 285-303.

[9]. Heidari E, Dickinson C, Wilson R, Fiske J (2007) Oral health of remand prisoners in HMP Brixton, London. British Dental Journal 9: 18-21.

[10]. McGrath C (2002) Oral health behind bars: a study of oral disease and its impact on the quality of an older prison population. Gerodontology 19(2): 109-114.

[11]. NHS Primary Care Contracting/ Faculty of General Dental Practice (UK) Guidelines for the appointment of Dentists with Special Interests (DwSIs) in Prison Dentistry 2005.

[12]. Silness J, Loe H (1964) Periodontal disease in preganancy II correlation between oral hygiene and periodontal condition. Acta Odontol Scand 22: 121-135.

[13]. Loe H, Silness J (1963) Periodontal disease in pregnancy I. prevalence and severity. Acta Odontol Scand 21: 533-551.

[14]. World Health Organization (1997) Oral health surveys: basic methods. (4th edtn), Geneva.

[15]. Colsher PL, Wallace RB, Loeffelholz PL, Sales M (1992) Health status of older male prisoners: a comprehensive survey. Am J Public Health 82(6):881-884.

[16]. Heng CK, Morse DE (2002) Dental caries experience of female inmates. J Public Health Dent 62(1): 57-61.

[17]. Mack F, Mojon P, Budtz-Jørgensen E, Kocher T, Splieth C, et al. (2004) Caries and periodontal disease of the elderly in Pomerania, Germany: results of the Study of Health in Pomerania. Gerodontology 21(1): 27-36.

[18]. Wyatt CC (2002) Elderly Canadians residing in long-term care hospitals: Part II. Dental caries status. J Can Dent Assoc 68(6): 359-363.

[19]. Bhat PK, Kadanakuppe S (2010) Periodontal health status and oral hygiene practices of Iruliga tribal community residing at Ramanagar district, Karnataka, India. J Int Oral Health 2(1): 17-21.

[20]. Elvin-Lewis M (1980) Plants used for teeth cleaning throughout the world. J Prev Dent 6: 61-70.

[21]. Bansal V, Sogi GM, Veeresha KL (2010) Assessment of Oral Health Status and Treatment needs of elders associated with elders' home of Ambala division, Haryana, India. Indian J Dent Res 21(2): 244-247.

[22]. Braimoh OB, Sofola OO, Okeigbemen SA (2011) Caries and periodontal health of prison inmates in Benin City, Nigeria. Int J Biomed Health Sci 7:137-145.

[23]. Burt B, Research, Science and Therapy Committee of the American Academy of Periodontology (2005) Position paper: epidemiology of periodontal diseases. J Periodontol 76(8): 1406-1419. 